\title{
A FORMAÇÃO DE DOIS CIRCUITOS DA ECONOMIA URBANA POR INTERMÉDIO DA AÇÃO DO Estado: o caso de CobiJa (Bolívia)
}

\author{
Leonardo Luiz Silveira da SILVA*
}

\begin{abstract}
RESUMO: Situada na periferia territorial boliviana, a cidade de Cobija, capital do Departamento de Pando, desfruta de uma política territorial especial: a regulamentação de uma Zona Franca. A ação do Estado no planejamento territorial permitiu realçar as premissas do modelo de Milton Santos (2004) dos dois circuitos da economia urbana. O estudo de caso em questão apresenta como o Estado pode, por meio de suas políticas que interferem na ordem mercantil, segregar espacialmente o tecido urbano e promover o arranjo da ordem social.
\end{abstract}

PALAVRAS-CHAVE: Zona Franca. Estado. Ordem Mercantil. Ordem Social.

\section{Introdução}

A cidade de Cobija, capital do Departamento de Pando, na Bolívia, desfruta de condição sui generis: situada na periferia territorial boliviana, em meio ao bioma amazônico, forma juntamente com as cidades brasileiras de Brasiléia e Epitaciolândia, uma conurbação transfronteiriça que as coloca na condição de cidades gêmeas. Portanto, formam por meio da conurbação uma região híbrida composta por elementos nacionais e internacionais, guardando para si uma identidade local única. (COELHO, 2013; TERENCIANI, 2012). A unicidade de suas características surge na literatura como um desafio para a elaboração de uma legislação que seja adequada às demandas locais. Silva e Oliveira (2008) destacam que se trata de uma estratégia de

\footnotetext{
IFNMG - Instituto Federal de Educação Ciência e Tecnologia do Norte de Minas Gerais - Campus
} Salinas. Salinas - MG - Brasil. 39560000 - leoluizbh@hotmail.com. 
grande parte dos pesquisadores de fronteira concentrar os seus estudos nas cidades gêmeas, onde melhor são esboçadas as interações das sociedades transfronteiriças. Nas cidades gêmeas, as assimetrias e simetrias entre sistemas territoriais nacionais e internacionais são mais visíveis, o que reforça o seu papel de alicerce da cooperação entre os países vizinhos. (MACHADO et. al., 2005).

As cidades gêmeas possuem a capacidade de articular as relações entre os países vizinhos que as abrigam. Tal articulação se dá em diversas escalas: a local, a regional, a nacional e até mesmo a internacional. As cidades gêmeas assumem, nesse sentido, um caráter de porta de entrada dos fluxos, concentrando-os e dispersandoos. As redes de transporte acabam por reforçar este caráter das cidades gêmeas ao se organizarem de tal modo que fazem das mesmas um importante nó de sua malha. Em muitos casos, as cidades gêmeas foram fundadas para promover a territorialização de facto nos confins territoriais do Estado, na sensível zona de fronteira. Ainda que muitas das ameaças do passado não prevaleçam na contemporaneidade, as cidades gêmeas permanecem como pontos de importante valor estratégico de um mundo menos conflitivo e mais cooperativo.

A Bolívia, que guarda um histórico relevante de perdas territoriais, apresenta políticas territoriais especiais mais agressivas, com vistas à promoção do desenvolvimento regional de uma área periferia e mal integrada às redes de transporte boliviano, do que aquelas apresentadas pelo lado brasileiro da conurbação. Assim como acontece em outros pontos estratégicos do território boliviano, são adotadas em Cobija as regras de uma Zona Franca, dotada de facilidades para a importação. Tal interferência do Estado, em porções específicas do território, colaborou para a modificação da realidade geográfica e social fazendo com que a produção do espaço urbano se arranje de modo a pronunciar explicitamente o modelo do circuito superior e inferior da economia urbana, teorizado por Milton Santos (2004).

O artigo em questão objetiva mostrar de que forma as políticas especiais praticadas pelo Estado, possibilitando a mercantilização anômala do espaço urbano, puderam refletir no arranjo geográfico e social de Cobija. Para tanto, apresenta aprioristicamente o histórico de perdas territoriais bolivianas, porque ele auxilia na compreensão da prática de políticas agressivas para o desenvolvimento da fronteira. Posteriormente são apresentados em sequência, dados das zonas francas bolivianas e demográficos da cidade de Cobija. Em seguida, é analisado o arranjo urbano do circuito superior e inferior da sua economia urbana, tendo como base os fundamentos do modelo de Milton Santos (2004). As reflexões foram endossadas por dois trabalhos de campo realizados na cidade, nos meses de janeiro dos anos de 2014 e 2015. 
A formação de dois circuitos da economia urbana por intermédio da ação do Estado: o caso de Cobija (Bolivia)

\section{MAPA 1: Posição de Cobija na Bolívia}

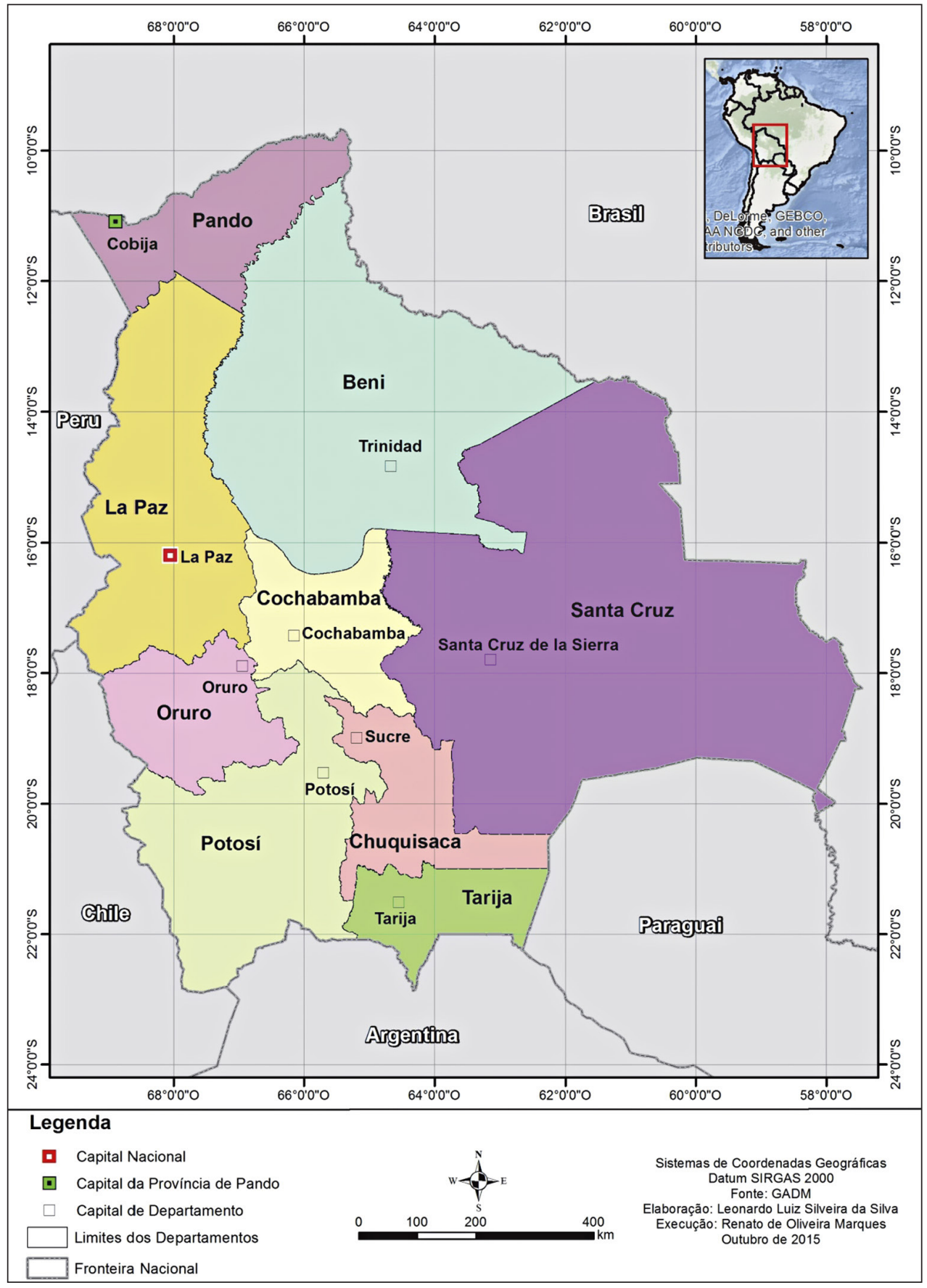


MAPA 2: A conurbação Brasiléia/Epitaciolândia/Cobija: arruamento básico

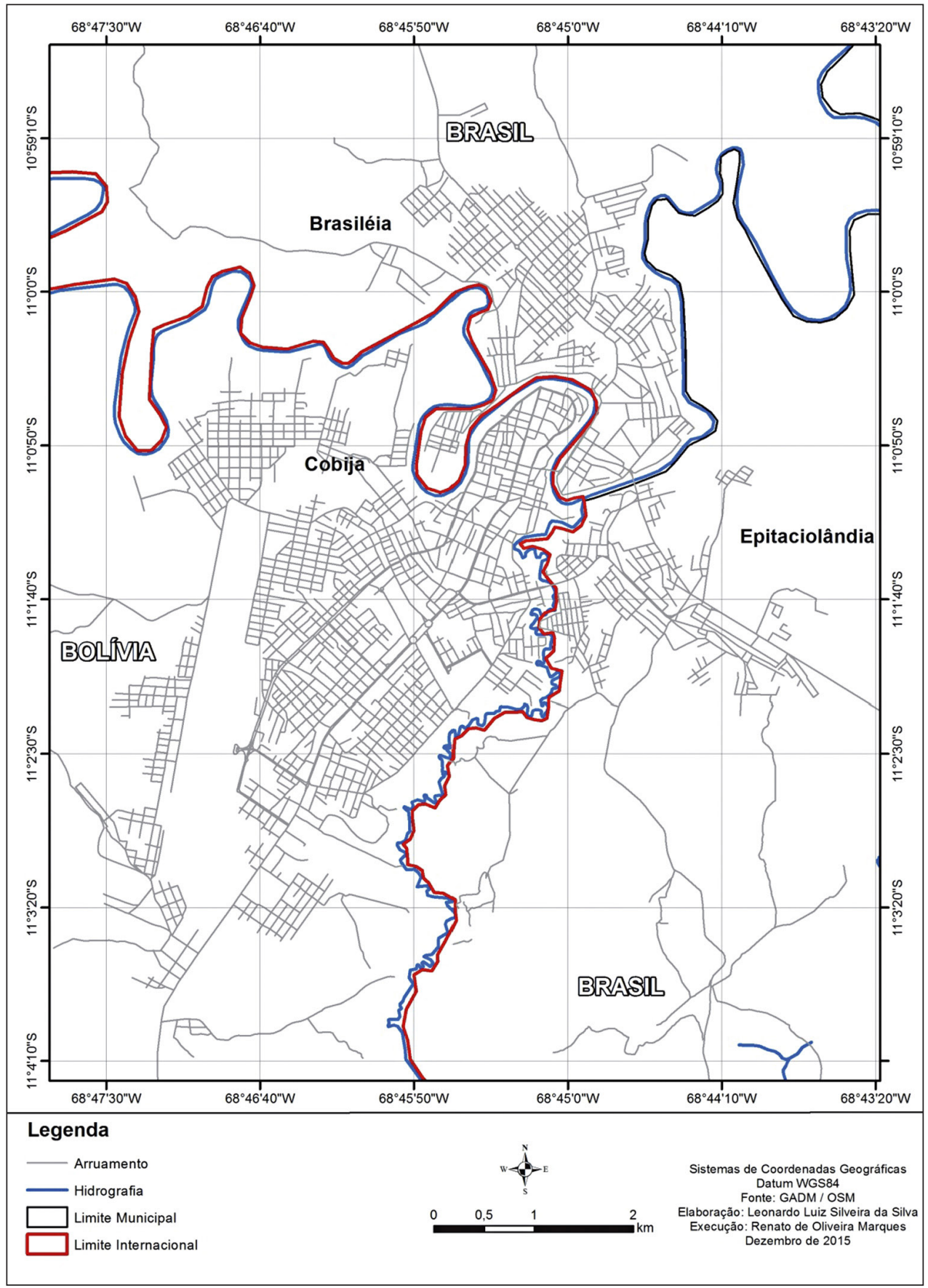




\section{A formaçāo de dois circuitos da economia urbana por intermédio da ação do Estado: o caso de Cobija (Bolivia)}

\section{Bolívia: histórico de perdas territoriais}

Para se compreender a dinâmica da dilapidação do território boliviano, devese analisar a sua constituição física no plano intranacional. Nesta análise estaremos diante de inúmeras dificuldades de conexão e imposição de redes no espaço boliviano (as redes são formidáveis agentes de territorialização), marcadas pelos inúmeros acidentes geográficos. Por outro lado, "deve-se destacar que as suas vastas riquezas naturais, ao mesmo tempo em que impulsionaram o desenvolvimento do país, também bafejaram a cobiça dos vizinhos". (DINIZ; CAMPOLINA, 2006, p.522). Tal argumento serve para a compreensão dos interesses dos brasileiros nos seringais bolivianos do Acre e do interesse chileno no salitre e posteriormente no cobre da antiga costa boliviana. O país ainda conta com reservas de gás e petróleo que foram almejadas por argentinos e paraguaios. Na contemporaneidade, o departamento de Santa Cruz, por exemplo, recebe investimentos brasileiros que visam a exploração destes recursos energéticos.

A região em questão era tida como um anecúmeno desprovido de valor econômico, embora, desde a independência boliviana em 1825, a área fosse tratada como território prioritário para o governo boliviano, sobretudo por representar a única saída marítima. Por um lado, a Bolívia apresentou dificuldades de ocupar a sua porção litorânea, e por outro, os chilenos foram motivados a, paulatinamente, ocupar a região ao norte de Antofagasta (porção extremo-setentrional do atual Chile). $\mathrm{O}$ fato da área ter sido considerada por muito tempo um deserto sem atratividade econômica, fez com que os limites entre Bolívia e Chile não fossem muito esclarecidos. Tudo mudou a partir de 1842, em função da descoberta da aplicabilidade agrícola do nitrato de sódio (salitre) e do guano (adubo rico em nitrogênio, proveniente das fezes de aves migratórias) presentes na região (REYES, 2009). Tal descoberta incentivou a exploração econômica chilena, deixando a Bolívia em posição desconfortável. Em 1878 o governo boliviano decidiu aumentar os impostos sobre o salitre exportado pelos chilenos para a Inglaterra, o que levou ao estado de guerra - Guerra do Pacífico (KLEIN, 2011). O Peru, que também possuía uma parte do seu território inserido na área em questão, lutou ao lado da Bolívia.

Com o triunfo chileno, o resultado foi a subtração de cerca de 120.000 quilômetros bolivianos (e também perdas peruanas), ainda hoje fonte de contestação boliviana. A busca pela saída marítima que foi perdida neste conflito pertence não somente ao pensamento da alta diplomacia, mas, a todo o seio da sociedade boliviana. 
FIGURA 1 - Adesivo alusivo à campanha pelo acesso territorial boliviano ao mar afixado na portaria da embaixada boliviana em Brasiléia

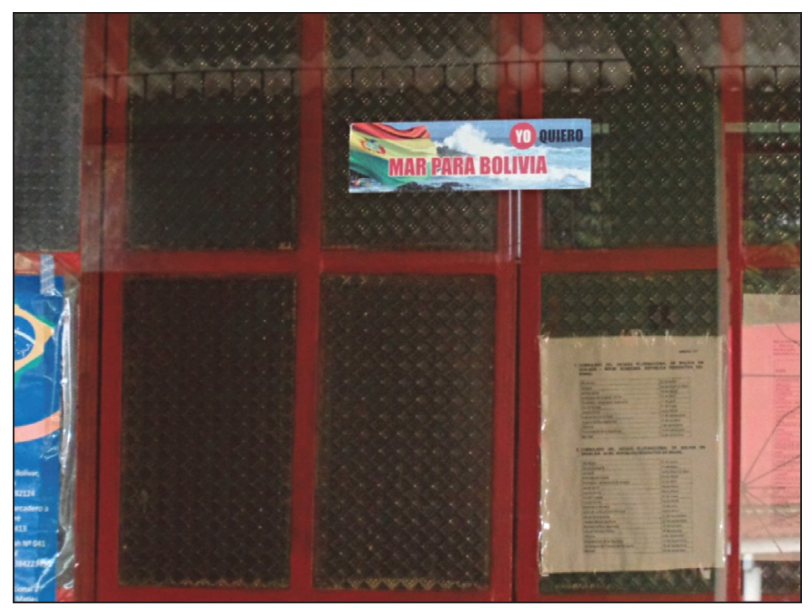

Fonte: Foto do autor

Embora pareça que a Guerra do Pacífico foi aquela que mais deixou sequelas no imaginário boliviano e nas relações contemporâneas com seus vizinhos, há outros eventos políticos responsáveis pela subtração de porções do território original do país. Destaca-se entre eles a Guerra do Chaco (1932-1935), que envolveu a Bolívia e o Paraguai. A planície do Chaco permitiria à Bolívia o acesso ao Rio Paraguai e daí ao rio da Prata, que conduz ao mar. Após a perda da saída marítima para o Chile, a posse do Chaco tornou-se estratégica. A dificuldade logística de apoio às tropas bolivianas (que estavam batalhando e marcando posições em locais distantes dos principais centros econômicos da Bolívia) facilitou a derrota inesperada com o saldo de 65.000 homens mortos e 240.000 quilômetros quadrados perdidos para o Paraguai. (REYES, 2009).

Entre a Guerra do Pacífico (1879-1884) e a Guerra do Chaco (1932-1935) se posiciona historicamente a Questão Acriana, que tem como desfecho o Tratado de Petrópolis (1903) e significou a subtração territorial do Acre. Somado a estes eventos estão inúmeras negociações diplomáticas com os seus vizinhos que conduziram a perdas no seu território original (a Bolívia cedeu terras através da via diplomática ou militar para todos os seus vizinhos). (DINIZ; CAMPOLINA, 2006). Inegavelmente, o histórico da formação territorial boliviana é marcado pelas perdas, o que contribui para o entendimento da gestão boliviana do seu território na contemporaneidade, bem como o seu posicionamento geopolítico. 


\section{A formação de dois circuitos da economia urbana por intermédio}

da ação do Estado: o caso de Cobija (Bolivia)

\section{MAPA 3 - Perdas Territoriais da Bolívia para o Brasil, Paraguai e Chile}

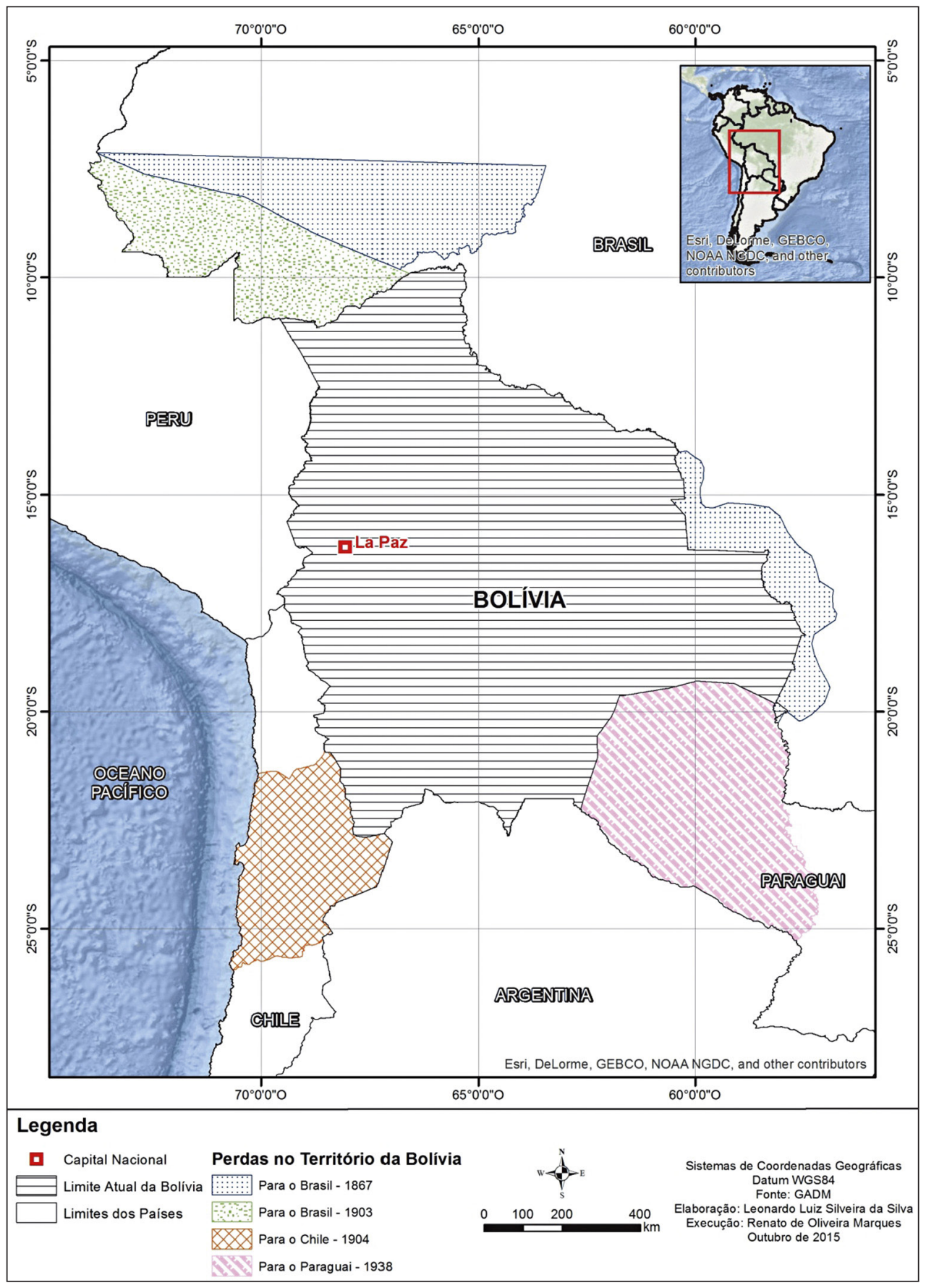




\section{Zonas francas bolivianas}

A Bolívia possui 15 zonas francas, sendo que as mesmas têm regulamentação distintas. Existem zonas francas de incentivo comercial, industrial e ambos. Parcela destas zonas francas situa-se junto aos limites internacionais, como é o caso das cidades gêmeas de Cobija, junto ao Brasil e Desaguadero, junto ao Peru. O grande número de zonas francas na Bolívia evidencia a importância desta estratégia como elemento de gestão territorial do país.

Zona Franca é a área estabelecida dentro do território nacional onde se pode introduzir - temporariamente -, à espera de um destino posterior, mercadorias nacionais ou estrangeiras sem submetê-las ao pagamento de impostos aduaneiros. O objetivo do regime é a geração de empregos sustentáveis e capacitação permanente, a atração de investimentos intensivos principalmente em mão de obra, a captação e desenvolvimento de tecnologia, a geração de valor agregado e o desenvolvimento de uma infraestrutura comercial, industrial e de serviços vinculados ao comércio internacional para a realização de processos produtivos destinados ao mercado interno e fundamentalmente às exportações e a facilitação do comércio. (BOLÍVIA, 2015, TRADUÇÃO NOSSA).

O quadro a seguir lista as zonas francas bolivianas, destacando aquelas que se situam junto ao limite territorial do país.

QUADRO 1 - Zonas Francas Bolivianas

\begin{tabular}{|c|c|c|c|}
\hline Zona Franca & Departamento & Tipo & $\begin{array}{c}\text { Situa-se junto } \\
\text { ao limite } \\
\text { internacional }\end{array}$ \\
\hline Desaguadero & La Paz & Comercial & Sim \\
\hline La Paz Comercial & La Paz & Comercial & Não \\
\hline $\begin{array}{c}\text { Zona Franca Industrial } \\
\text { GIT La Paz }\end{array}$ & La Paz & Industrial & Não \\
\hline Zona Franca de Patacamaya & La Paz & Industrial & Não \\
\hline Cochabamba & Cochabamba & Comercial e Industrial & Não \\
\hline Puerto Aguirre & Santa Cruz & Comercial & Sim \\
\hline Puerto Suarez & Santa Cruz & Comercial e Industrial & Sim \\
\hline Santa Cruz Winner & Santa Cruz & Comercial e Industrial & Não \\
\hline Santa Cruz Warnes & Santa Cruz & Comercial e Industrial & Não \\
\hline
\end{tabular}




\section{A formaçāo de dois circuitos da economia urbana por intermédio da ação do Estado: o caso de Cobija (Bolivia)}

\begin{tabular}{|c|c|c|c|}
\hline Zona Franca & Departamento & Tipo & $\begin{array}{c}\text { Situa-se junto } \\
\text { ao limite } \\
\text { internacional }\end{array}$ \\
\hline Zona Franca de San Matías & Santa Cruz & Comercial & Sim \\
\hline Oruro & Oruro & Comercial e Industrial & Não \\
\hline Villazón & Potosi & Comercial & Não \\
\hline Yacuiba & Tarija & Comercial & Não \\
\hline Guayaramirim & Beni & Comercial & Sim \\
\hline Cobija & Pando & Comercial e Industrial & Sim \\
\hline
\end{tabular}

Fonte: BOLÍVIA, 2015, organizado pelo autor.

As aglomerações urbanas de Puerto Aguirre, Puerto Suarez, San Matías, Guayaramirim e Cobija, que são contempladas pelo regime da Zona Franca, se situam junto ao limite com o Brasil. O desenvolvimento econômico das áreas lindeiras, que já é uma estratégia importante para a maioria dos países, parece ser uma das políticas prioritárias da gestão do território boliviano, fato que encontra explicação no seu histórico de subtrações territoriais, como já foi visto. Outra explicação é a assimetria entre as exportações e as importações bolivianas, que se manifesta à medida em que o país, frente a maioria dos seus parceiros comerciais, apresenta baixa diversificação econômica, fazendo com que as exportações se concentrem em poucos produtos e as importações se distribuam em vários produtos, como pode ser visto nas TABELAS 1 e 2, que mostram as relações comerciais Bolívia-Brasil.

TABELA 1 - Os dez principais produtos exportados pela Bolívia ao Brasil de Janeiro a Agosto de 2014 e 2015

\begin{tabular}{ccccc}
\hline \multirow{2}{*}{ Produto } & \multicolumn{2}{c}{ 2014 (JAN/AGO) } & \multicolumn{2}{c}{ 2015 (JAN/AGO) } \\
\cline { 2 - 5 } & $\begin{array}{c}\text { Valor em } \\
\text { US\$ FOB }\end{array}$ & $\begin{array}{c}\text { Participação } \\
\text { Relativa \% }\end{array}$ & $\begin{array}{c}\text { Valor em } \\
\text { US\$ FOB }\end{array}$ & $\begin{array}{c}\text { Participação } \\
\text { Relativa \% }\end{array}$ \\
\hline Gás Natural Gasoso & 2.589 .789 .295 & 98,29 & 1.778 .780 .668 & 98,18 \\
\hline Boratos Naturais & 16.662 .139 & 0,63 & 10.614 .029 & 0,59 \\
\hline Feijão & 7.098 .703 & 0,27 & 4.828 .060 & 0,27 \\
Madeira & 2.532 .875 & 0,10 & 2.839 .762 & 0,16 \\
\hline Resíduo de Alumínio & 1.868 .030 & 0,07 & 2.628 .018 & 0,15 \\
\hline $\begin{array}{c}\text { Trióxido de } \\
\text { Antimônio }\end{array}$ & 2.515 .705 & 0,10 & 1.918 .802 & 0,11 \\
\hline
\end{tabular}




\begin{tabular}{ccccc}
\hline \multirow{2}{*}{ Produto } & \multicolumn{2}{c}{$\mathbf{2 0 1 4}$ (JAN/AGO) } & \multicolumn{2}{c}{ 2015 (JAN/AGO) } \\
\cline { 2 - 5 } & $\begin{array}{c}\text { Valor em } \\
\text { US\$ FOB }\end{array}$ & $\begin{array}{c}\text { Participação } \\
\text { Relativa \% }\end{array}$ & $\begin{array}{c}\text { Valor em } \\
\text { US\$ FOB }\end{array}$ & $\begin{array}{c}\text { Participação } \\
\text { Relativa \% }\end{array}$ \\
\hline $\begin{array}{c}\text { Sementes Forrageiras } \\
\text { Grãos de outros }\end{array}$ & 971.633 & 0,04 & 1.422 .219 & 0,08 \\
cereais & 784.954 & 0,03 & 720.742 & 0,04 \\
Feltro para chapéus & 763.457 & 0,03 & 673.000 & 0,04 \\
Quinoa & 1.505 .456 & 0,06 & 644.400 & 0,04 \\
Outros & 10.323 .730 & 0,38 & 6.614 .691 & 0,34 \\
Total & 2.634 .815 .977 & 100,00 & 1.811 .684 .391 & 100,00 \\
\hline
\end{tabular}

Fonte: MINISTÉRIO DAS RELAÇÕES EXTERIORES, 2015.

TABELA 2 - Principais produtos brasileiros importados pela Bolívia em dólares de janeiro a agosto de 2014 e 2015

\begin{tabular}{|c|c|c|c|c|}
\hline \multirow[b]{2}{*}{ Produto } & \multicolumn{2}{|c|}{2014 JAN/AGO } & \multicolumn{2}{|c|}{2015 JAN/AGO } \\
\hline & US\$ FOB & $\begin{array}{c}\text { Participação } \\
\text { Relativa \% }\end{array}$ & US\$ FOB & $\begin{array}{c}\text { Participação } \\
\text { Relativa }\end{array}$ \\
\hline Barras de Ferro & 102.064 .849 & 10,00 & 76.808 .254 & 8,09 \\
\hline $\begin{array}{l}\text { Betume de } \\
\text { Petróleo }\end{array}$ & 28.150 .707 & 2,76 & 22.560 .398 & 2,38 \\
\hline Tratores & 22.454 .395 & 2,20 & 20.084 .816 & 2,11 \\
\hline $\begin{array}{l}\text { Condutores } \\
\text { elétricos }\end{array}$ & 19.231 .084 & 1,88 & 16.497 .144 & 1,74 \\
\hline Polietilenos & 19.303.977 & 1,89 & 14.345 .871 & 1,51 \\
\hline Móveis de madeira & 11.909 .803 & 1,17 & 11.795 .663 & 1,24 \\
\hline Polipropilenos & 16.848 .487 & 1,65 & 11.771 .963 & 1,24 \\
\hline Papel & 11.172 .540 & 1,09 & 10.971 .748 & 1,16 \\
\hline Arroz & 14.626 .664 & 1,43 & 10.014 .430 & 1,05 \\
\hline $\begin{array}{l}\text { Locomotivas à } \\
\text { diesel-elétricas }\end{array}$ & Sem registro & Sem registro & 9.557 .056 & 1,01 \\
\hline $\begin{array}{c}\text { Total dos } 100 \\
\text { principais } \\
\text { produtos }\end{array}$ & 567.341 .626 & 55,60 & 549.167 .332 & 57,82 \\
\hline Total Geral & 1.020 .463 .767 & 100,00 & 949.863 .230 & 100,00 \\
\hline
\end{tabular}

Fonte: MINISTÉRIO DAS RELAÇÕES EXTERIORES, 2015. 


\section{A formaçāo de dois circuitos da economia urbana por intermédio da ação do Estado: o caso de Cobija (Bolivia)}

\section{Zona Franca de Cobija}

Os primeiros benefícios fiscais concedidos à Cobija, capital do Departamento de Pando, datam de setembro de 1965. Desde então, a legislação se modificou várias vezes até chegar ao atual formato. A Zona Franca de Cobija propriamente dita foi criada em 1983, sendo a primeira experiência deste tipo no território boliviano. (MACHADO; RIBEIRO; MONTEIRO, 2014). Os benefícios da Zona Franca se estendem às atividades industriais e comerciais, válidos para a área urbana de Cobija. Em 2012, cerca de 110 milhões de dólares entraram na área da Zona Franca, sendo que a taxa de crescimento anual oscila de 10 a 15\%. Em 2011, 49\% das mercadorias que foram importadas pela Zona Franca vieram do Chile. No mesmo ano, cerca de $34 \%$ vieram do Brasil e $11 \%$ dos Estados Unidos. Recentemente, as importações diretas da China têm registrado aumento. (LA ZONA FRANCA, 2013).

Na Zona Franca de Cobija, os importadores só pagam 1,5\% pela internação das mercadorias, sendo que estes recursos são transferidos ao Tesouro Geral da Nação (TGN). Contudo, todas as mercadorias que são vendidas deverão gerar notas fiscais, sendo que o lucro do vendedor é passível de ser tributado. (LA ZONA FRANCA, 2013). Este é o motivo de podermos ver na paisagem urbana alguns estabelecimentos fechados. A existência de estabelecimentos fechados em diversos pontos da cidade sugere a atuação de uma fiscalização efetiva.

Em 2006 encontravam-se instaladas em Cobija 208 empresas, sendo que, deste montante, somente $10 \%$ pertenciam a estrangeiros (MACHADO; RIBEIRO; MONTEIRO, 2014). Estima-se que nessa Zona Franca cerca de 90\% dos compradores sejam brasileiros (LA ZONA FRANCA, 2013). Nesse sentido, a variação cambial no Brasil pode impactar dramaticamente nas suas vendas. A alta do dólar registrada no período 2014-2016, diminuiu a participação de brasileiros nas vendas, pois o produto internado na Zona Franca perdeu a competitividade. Por outro lado, um cenário contrário (de queda do dólar) tende a estimular a compra de brasileiros, pois o produto vendido no comércio da Zona Franca ganha competitividade.

Nem todas as empresas de Cobija são usuárias da regulamentação da Zona Franca. Em dezembro de 2011 estavam registrados 153 usuários, sendo que 15\% destes se encontravam inativos (se registraram somente para efetuar uma ou poucas importações) (CARLO, 2013). 
FIGURA 2 - Estabelecimento comercial fechado pelo não recolhimento de impostos na Zona Franca de Cobija

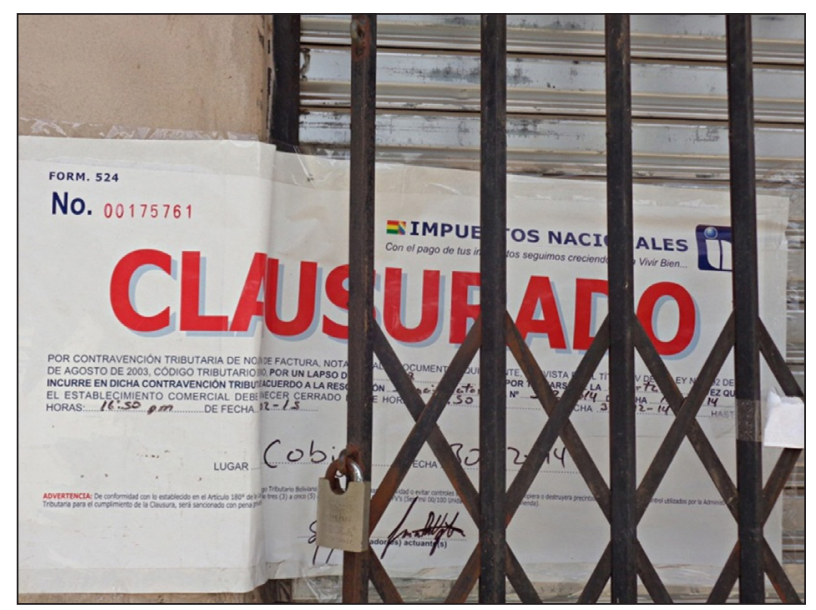

Fonte: Foto do autor

\section{Aspectos demográficos de Cobija}

Apesar do município de Cobija apresentar a menor população dentre as capitais departamentais bolivianas (46.267 habitantes), exibe, por outro lado, forte crescimento demográfico relativo, como atestam os dados a seguir.

FIGURA 3 - Crescimento populacional de Cobija

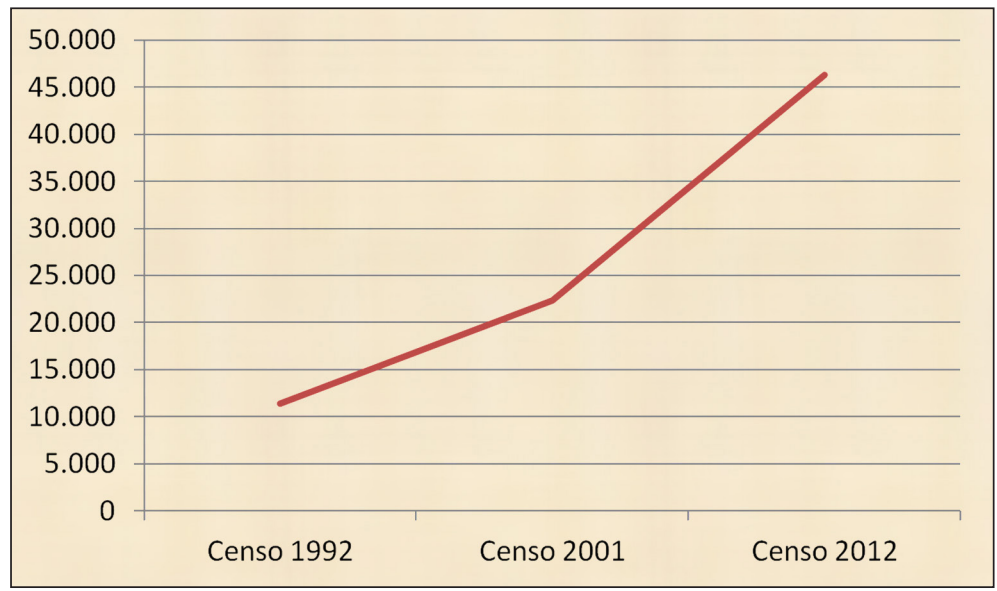

Fonte: INE, 2015d, 2015c, 2015e 


\section{A formaçāo de dois circuitos da economia urbana por intermédio}

da ação do Estado: o caso de Cobija (Bolivia)

TABELA 3 - Município de Cobija: Taxa de crescimento entre censos 2001 e 2012

\begin{tabular}{c|c|c|c|c}
\hline $\mathbf{2 0 0 1}$ & $\mathbf{2 0 1 2}$ & $\begin{array}{c}\text { Crescimento } \\
\text { absoluto }\end{array}$ & $\begin{array}{c}\text { Crescimento } \\
\text { relativo }\end{array}$ & $\begin{array}{c}\text { Taxa média de } \\
\text { crescimento } \\
\text { anual }\end{array}$ \\
\hline 22.324 & 46.267 & 23.943 & $107,3 \%$ & $6,5 \%$ \\
\hline
\end{tabular}

Fonte: INE, 2015a, 2015b.

O Departamento de Pando é fracamente povoado no comparativo com os demais departamentos bolivianos. Cobija, contudo, concentra uma parcela importante da população total da sua província e do seu departamento, conforme atestam as informações a seguir.

FIGURA 4 - Concentração da população da província de Nícolas Suarez e do Departamento de Pando na cidade de Cobija

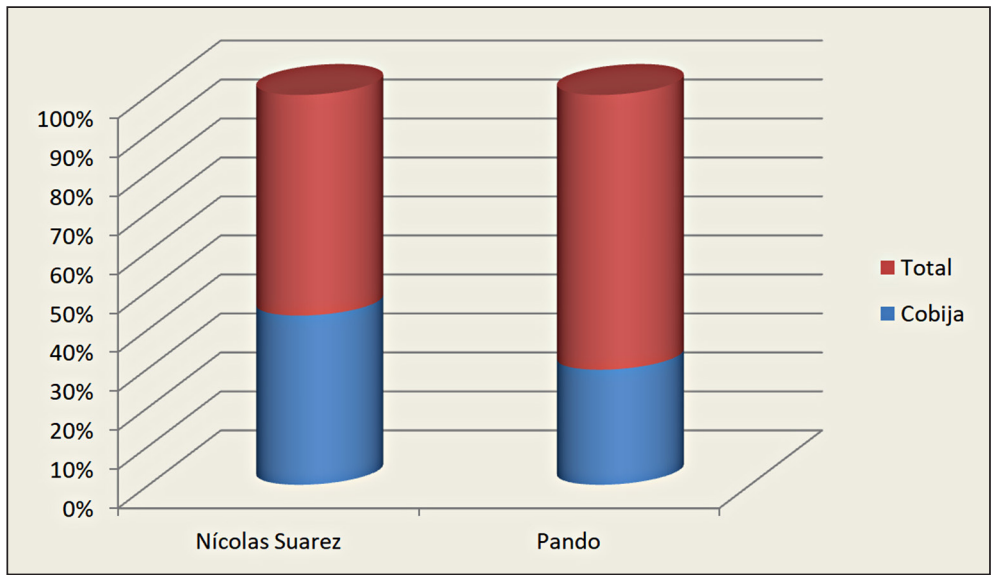

Fonte: INE, 2015d

TABELA 4 - População do departamento de Pando por município

\begin{tabular}{cc}
\hline Município & População \\
\hline Cobija & 46.267 \\
Sena & 8.258 \\
$\begin{array}{c}\text { Puerto Gonzales } \\
\text { Moreno }\end{array}$ & 8.160 \\
\hline Porvenir & 7.948
\end{tabular}




\begin{tabular}{cc}
\hline Município & População \\
\hline San Lorenzo & 7.652 \\
\hline Puerto Rico & 6.239 \\
\hline Filadelfia & 5.756 \\
\hline Bella Flor & 3.909 \\
\hline San Pedro & 2.991 \\
\hline Villa Nueva & 2.801 \\
\hline Santa Rosa & 2.395 \\
\hline Bolpebra & 2.173 \\
\hline Santos Mercado & 2.165 \\
\hline Nueva Esperanza & 2.068 \\
\hline Ingavi & 1.654 \\
\hline Total & 110.436 \\
\hline
\end{tabular}

Fonte: INE, 2015d.

A TABELA 5 expressa a pequena participação de Pando no conjunto da população total boliviana, o que reforça o seu papel periférico dentro do conjunto territorial que integra.

TABELA 5 - Participação absoluta e relativa dos departamentos bolivianos no conjunto da população do país.

\begin{tabular}{ccc}
\hline Departamento & População & Concentração relativa \\
\hline Chuquisaca & 581.347 & $5,78 \%$ \\
\hline La Paz & 2.719 .344 & $27,03 \%$ \\
\hline Cochabamba & 1.762 .761 & $17,52 \%$ \\
\hline Oruro & 494.587 & $4,92 \%$ \\
\hline Potosí & 828.093 & $8,23 \%$ \\
\hline Tarija & 483.518 & $4,81 \%$ \\
\hline Santa Cruz & 2.657 .762 & $26,42 \%$ \\
\hline Beni & 422.008 & $4,19 \%$ \\
\hline Pando & 110.436 & $1,10 \%$ \\
\hline Total & 10.059 .856 & $100 \% *$ \\
\hline
\end{tabular}

Fonte: INE, 2015d. * Os valores não totalizam 100\% devido aos arredondamentos. 
O rápido crescimento demográfico de Cobija explica a característica marcante da naturalidade de sua população: uma parcela expressiva dos seus habitantes não nasceu na capital de Pando, como atestam os dados a seguir, indicando o caráter de cidade de oportunidades que se consolidou com a implementação e a expansão na Zona Franca.

TABELA 6 - Naturalidade do habitante de Cobija

\begin{tabular}{cccc}
\hline Local de nascimento & Total & Homens & Mulheres \\
\hline Cobija & 24.022 & 11.869 & 12.153 \\
\hline $\begin{array}{c}\text { Em outro lugar do } \\
\text { País }\end{array}$ & 21.279 & 11.673 & 9.606 \\
No exterior & 966 & 436 & 530 \\
\hline Total & 46.267 & 23.978 & 22.289 \\
\hline
\end{tabular}

Fonte: INE, 2015d.

Apesar de quase a metade da população de Cobija não ter nascido na cidade, existe fidelidade entre os que hoje a habitam e o município. A maioria expressiva da população faz da mesma o seu principal local de residência, como pode ser observado na TABELA 7.

TABELA 7 - Local de residência habitual do entrevistado pelo INE em Cobija

\begin{tabular}{cccc}
\hline Local de residência habitual & Total & Homens & Mulheres \\
Cobija & 45.434 & 23.500 & 21.934 \\
\hline Em outro lugar do país & 777 & 449 & 328 \\
No exterior & 56 & 29 & 27 \\
Total & 46.267 & 23.978 & 22.289 \\
\hline
\end{tabular}

Fonte: INE, 2015d.

A população de Cobija possui a razão de sexo pendendo a favor dos homens e uma característica essencialmente urbana, como atesta a TABELA 8. 


\begin{tabular}{cccc} 
TABELA 8 & Município de Cobija: População por área e \\
por sexo a partir de dados do Censo de & 2012 \\
\hline Área & Mulheres & Homens & Total \\
\hline Urbana & 21.445 & 22.675 & 44.120 \\
Rural & 844 & 1.303 & 2.147 \\
Total & 22.289 & 23.978 & 46.267 \\
\hline
\end{tabular}

Fonte: INE, 2015d.

A diferença entre homens e mulheres se expressa através do seguinte número: $48,6 \%$ da população de Cobija é composto por mulheres, tendência que acompanha a cidade há pelo menos três recenseamentos.

\section{Circuito inferior e superior da economia urbana de Cobija}

A produção do espaço urbano de Cobija foi muito influenciada pelas legislações especiais que disponibilizaram vantagens comparativas no que tange às importações internadas no espaço intramunicipal. A cidade tem vantagens ligadas à sua posição urbana, uma vez que desfruta também do status de cidade gêmea, conurbada às cidades brasileiras de Brasiléia e Epitaciolândia. As cidades brasileiras em questão, de menor porte, (somam juntas cerca de 40.000 habitantes), não oferecem séria concorrência comercial à capital do Departamento de Pando, o que encontra explicação no fato da legislação das mesmas não permitir vantagens nas importações. Assim, Cobija reina no que tange à oferta de produtos americanos e europeus, a preços competitivos, na região em que está inserida. Há de se ressaltar que os brasileiros, que compõem a maior parcela da clientela da Zona Franca de Cobija (estima-se em 90\% deste mercado), são sensíveis às oscilações cambiais, fazendo com que as receitas da cidade boliviana oscilem ao sabor do enfraquecimento ou fortalecimento do real frente ao dólar.

O quadro desenhado para Cobija ressalta para a cidade boliviana, de forma acentuada, o modelo de Milton Santos (2004) apresentado na obra $O$ Espaço Dividido. Trata-se do modelo dos dois circuitos da economia urbana dos países subdesenvolvidos. Apresentaremos as premissas do modelo de Santos para posteriormente inferirmos o papel das políticas territoriais especiais bolivianas para que tal modelo fosse realçado no espaço intramunicipal de Cobija.

Para Milton Santos (2004, p. 20), “os espaços dos países subdesenvolvidos caracterizam-se primeiramente pelo fato de se organizarem e reorganizarem em 


\section{A formaçāo de dois circuitos da economia urbana por intermédio da ação do Estado: o caso de Cobija (Bolivia)}

função de interesses distantes, sendo que não são atingidos de um modo maciço pelas forças de transformação", cujo impacto é localizado, ou seja, centrado em determinadas áreas em detrimento de outras. Ele considera ainda que a "cada modernização, novos pontos ou novas zonas são conquistas ao espaço neutro e tornam-se uma nova porção de espaço operacional" e conclui a partir desse raciocínio que o impacto dessas forças modernizadoras "não é o mesmo para as diversas variáveis, cuja combinação dá a caraterística do lugar", disso resultando "uma grande instabilidade na organização do espaço com repetidos desequilíbrios e ajustamentos" (SANTOS, 2004, p.20-21).

Por intermédio desse raciocínio, Santos (2004) preconiza que as forças hegemônicas que atuam na produção do espaço auxiliam na construção de paisagens heterogêneas a medida em que fatias do espaço podem ser mais ou menos atrativas a sua atuação. $O$ raciocínio condiz com outras passagens do conjunto de sua obra, quando argumenta que as diferenças das técnicas empregadas garantem a perpetuação da desigualdade do espaço (SANTOS, 2012a) ou ainda, que a paisagem é o conjunto de formas que, num dado momento, exprimem as heranças que representam as sucessivas relações localizadas entre o homem e a natureza, residindo nela as rugosidades espaciais (SANTOS, 2012b).

Assim, na obra $O$ Espaço Dividido, Milton Santos (2004) apresenta um modelo de leitura do arranjo urbano das cidades subdesenvolvidas, que apresentaria notória ruptura que daria origem a duas unidades regionais, batizadas como o circuito inferior e o circuito superior da economia urbana. Nas palavras do autor,

O circuito superior originou-se diretamente da modernização tecnológica e os seus elementos mais representativos hoje são os monopólios. O essencial de suas relações ocorre fora da cidade e da região que os abrigam e tem por cenário o país ou o exterior. O circuito inferior, formado de atividades de pequena dimensão e interessando principalmente às populações pobres, é, ao contrário, bem enraizado e mantém relações privilegiadas com sua região. (SANTOS, 2004, p.22).

Milton Santos (2004) sintetizou o modelo em que aponta a dicotomia expressa pelos alardeados circuitos da economia urbana. Tal quadro, reproduzido a seguir, aponta para diferenças que repercutem nas esferas econômica e social, caracterizando os dois circuitos. 
QUADRO 2: Características dos dois circuitos da economia urbana dos países subdesenvolvidos

\begin{tabular}{|l|l|l|}
\hline & \multicolumn{1}{|c|}{ Circuito Superior } & \multicolumn{1}{c|}{ Circuito Inferior } \\
\hline Tecnologia & capital intensivo & trabalho intensivo \\
\hline Organização & Burocrática & Primitiva \\
\hline Capitais & Importantes & Reduzidos \\
\hline Emprego & Reduzido & Volumoso \\
\hline Assalariado & Dominante & não-obrigatório \\
\hline Estoques & $\begin{array}{l}\text { grande quantidade e/ou alta } \\
\text { qualidade }\end{array}$ & $\begin{array}{l}\text { pequena quantidade/ } \\
\text { qualidade inferior }\end{array}$ \\
\hline Preços & fixos (em geral) & $\begin{array}{l}\text { submetidos à discussão } \\
\text { entre comprador e vendedor } \\
\text { (haggling) }\end{array}$ \\
\hline Crédito & bancário institucional & pessoal não institucional \\
\hline Margem de Lucro & $\begin{array}{l}\text { reduzida por unidade, mas } \\
\text { importante pelo volume de } \\
\text { negócios (com a exceção de } \\
\text { produtos de luxo) }\end{array}$ & $\begin{array}{l}\text { elevada por unidade, mas } \\
\text { pequena em relação ao } \\
\text { volume dos negócios }\end{array}$ \\
\hline Relações com a Clientela & Impessoais & diretas, personalizadas \\
\hline Custos Fixos & Importantes & Desprezíveis \\
\hline Publicidade & Necessária & Nula \\
\hline Reutilização dos bens & Nula & Frequente \\
\hline Overhead Capital & Indispensável & Dispensável \\
\hline Ajuda Governamental & Importante & nula ou quase nula \\
\hline Dependência direta do \\
exterior & $\begin{array}{l}\text { grande, atividade voltada } \\
\text { para o exterior }\end{array}$ & reduzida ou quase nula \\
\hline Fion & & \\
\hline
\end{tabular}

Fonte: SANTOS (2004)

A cidade de Cobija, submetida à legislação de Zona Franca Boliviana, aglutinou em sua porção central, próxima a ponte Wilson Pinheiro (que liga as cidades de Cobija e Brasiléia), o seu circuito superior da economia urbana. Importadores trazem produtos de diversos países e se apropriam das áreas mais valorizadas e verticalizadas da cidade para comercializarem. Nesta área, os estabelecimentos comerciais possuem a clientela mais voltada ao exterior do que para a própria cidade. Assim, o circuito superior da sua economia urbana se associa 


\section{A formação de dois circuitos da economia urbana por intermédio da ação do Estado: o caso de Cobija (Bolivia)}

tanto no abastecimento de produtos para revenda quanto para a comercialização internacional. Lojas varejistas e atacadistas se distribuem na área central com grandes estoques e estabelecem relações impessoais com a clientela, composta por maioria de brasileiros. Destacam-se entre os produtos comercializados as bebidas, eletrônicos, perfumes e itens de vestuário de alto padrão. Preços fixos e relação impessoal inibem a barganha no circuito superior.

A atratividade que a função comercial que Cobija desempenha vai além do estado do Acre, atraindo brasileiros de múltiplas localidades, conforme foi possível observar nas informações sobre a origem dos hóspedes de hotéis selecionados, coletadas em trabalho de campo na cidade.

TABELA 9 - Local de residência dos hóspedes de cinco hotéis de Cobija em distintos períodos entre janeiro de 2014 e janeiro de 2015

\begin{tabular}{ccc}
\hline Cidade & Estado/País & N $^{\mathbf{0}}$ de hóspedes \\
\hline La Paz & Bolívia & 791 \\
\hline Santa Cruz de la Sierra & Bolívia & 452 \\
\hline Cochabamba & Bolívia & 234 \\
\hline Rio Branco & Acre/Brasil & 173 \\
\hline Trinidad & Bolívia & 161 \\
\hline Potosí & Bolívia & 138 \\
\hline Oruro & Bolívia & 111 \\
\hline Sucre & Bolívia & 78 \\
\hline Cobija & Bolívia & 55 \\
\hline Tarija & Bolívia & 48 \\
\hline Lima & Peru & 44 \\
\hline Porto Velho & Rondônia/Brasil & 39 \\
\hline Riberalta & Bolívia & 25 \\
\hline Santana del Yacuna & Bolívia & 13 \\
\hline Guayaramerín & Bolívia & 12 \\
\hline Puerto Maldonado & Peru & 10 \\
\hline Brasileia & Acre/Brasil & 7 \\
\hline Oklahoma & Estados Unidos & 6 \\
\hline Iquique & Chile & 5 \\
\hline Manaus & Amazonas/Brasil & 5 \\
\hline
\end{tabular}




\begin{tabular}{|c|c|c|}
\hline Cidade & Estado/País & $\mathrm{N}^{0}$ de hóspedes \\
\hline Tambopata & Peru & 5 \\
\hline Puno & Peru & 4 \\
\hline Trujillo & Peru & 4 \\
\hline Buenos Aires & Argentina & 3 \\
\hline Cuzco & Peru & 3 \\
\hline Porto Rico & Bolívia & 3 \\
\hline Tokyo & Japão & 3 \\
\hline Zurique & Suíça & 3 \\
\hline Altstatten & Suíça & 2 \\
\hline Beijing & China & 2 \\
\hline Fortaleza & Ceará/Brasil & 2 \\
\hline Reyes & Bolívia & 2 \\
\hline San José & Costa Rica & 2 \\
\hline Santiago del Chile & Chile & 2 \\
\hline São Paulo & São Paulo/Brasil & 2 \\
\hline Texas & Estados Unidos & 2 \\
\hline Belo Horizonte & Minas Gerais & 2 \\
\hline Outras & & 32 \\
\hline Total & & 2485 \\
\hline
\end{tabular}

Fonte: Levantamento das fichas cadastrais dos hóspedes junto à administração dos hotéis Nanijos, El Cristo, Avenida, Diana e Paititi, realizado pelo autor.

Como foi apresentado, Rio Branco, Porto Velho, Manaus, São Paulo, Fortaleza e Belo Horizonte são municípios de origem de alguns hóspedes, no ínterim de janeiro de 2014 a janeiro de 2015, com forte concentração nas duas primeiras. Outras cidades internacionais em relação à Cobija foram exibidas como origem do hóspede, o que atesta certo cosmopolitismo, construído, por sua vez, pelas redes transnacionais cuja cidade desfruta do status de nó. Este status é facilitado também pela existência de um aeroporto, ainda que o mesmo não opere em linhas diretamente ligadas ao exterior (é necessária a escala em La Paz). 
A formação de dois circuitos da economia urbana por intermédio da ação do Estado: o caso de Cobija (Bolivia)

FIGURA 5 - Aspecto do circuito superior da economia urbana de Cobija - Calle Enrique Fernandez Cornejo

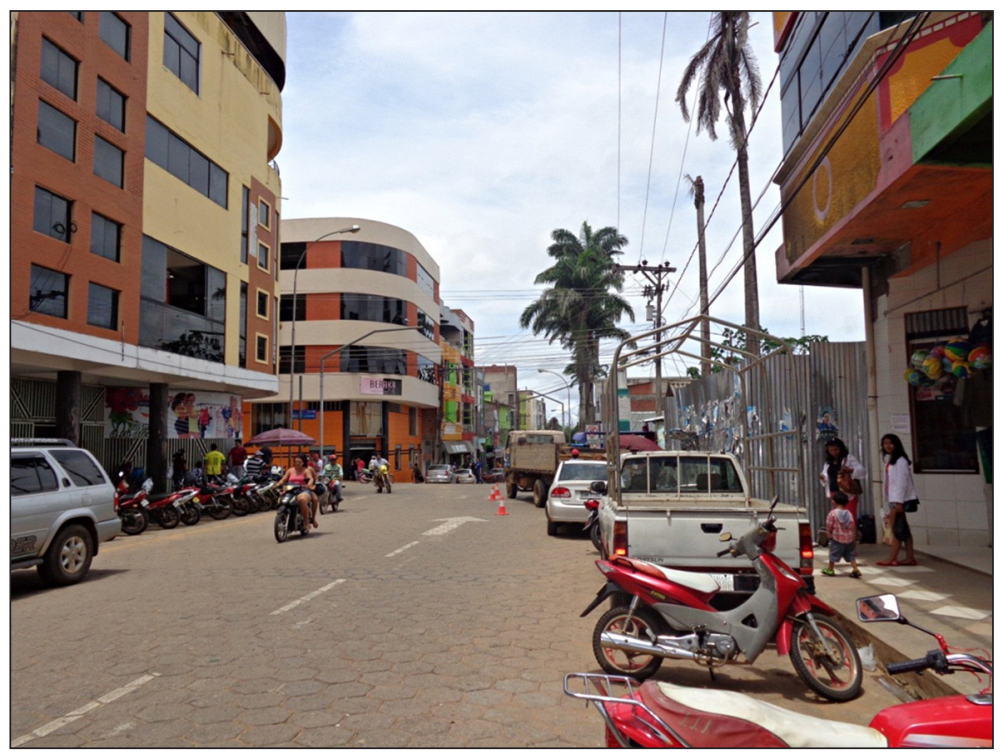

Fonte: Foto do autor

FIGURA 6 - Aspecto do circuito superior da economia urbana de Cobija - Calle Enrique Fernandez Cornejo

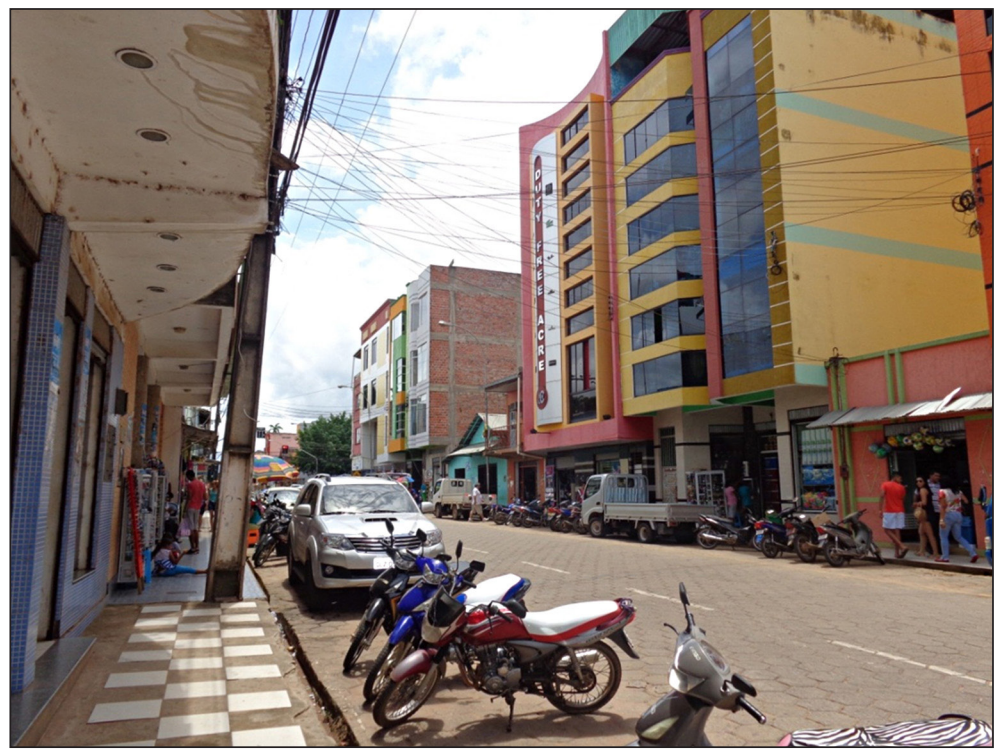

Fonte: Foto do autor 
Concomitantemente à existência do circuito superior da economia urbana, opera o circuito inferior da economia, composto por pequenos comerciantes dotados de lojas de pequeno estoque, em que a barganha é possível e a relação entre proprietário e cliente é mais próxima. O circuito inferior é mais extenso em superfície do que o circuito superior, sendo basicamente composto por itens de alimentação e vestuário (itens de consumo básico). Os itens de vestuário são abastecidos, principalmente, pelas indústrias têxteis de Santa Cruz de La Sierra, tanto as peças novas quanto as de segunda mão (existe uma rede de distribuição de roupas de segunda mão no território boliviano que tem Santa Cruz de La Sierra como importante nó) (OLIVEIRA; FERREIRA, 2015).

Contudo, há em Cobija uma incongruência frente aos pressupostos do modelo de Milton Santos (2004). No circuito inferior, pelo menos no que tange aos pequenos mercados responsáveis pelo abastecimento de itens de alimentação, existe forte relação com o exterior. Parcela importante dos itens industrializados de alimentação é de origem brasileira. Tal fato se explica pelas condições de exceção que envolvem a Bolívia e a posição urbana de Cobija. O fato da Bolívia ser um país fracamente industrializado e com a economia pouco diversificada, ajuda a entender a dependência. $\mathrm{O}$ abastecimento de itens predominantemente brasileiros se justifica pelo caráter lindeiro da posição urbana de Cobija. Além disso, há de se considerar que ela é vizinha de dois municípios brasileiros que desfrutam do regime de Área de Livre Comércio, o que faz com que os mesmos possam internar mercadorias de diversas regiões do Brasil com descontos expressivos no Imposto sobre Circulação de Mercadorias (ICMS). Apesar de não estar regulamentada a permissão de exportação com vantagens comparativas, é plausível considerar que os mercados de Brasiléia e Epitaciolândia abastecem o circuito inferior de Cobija, fato que encontra a plausibilidade justamente pelo pequeno estoque dos estabelecimentos bolivianos, o que facilita a sua reposição por intermédio de fluxos não declarados/ ilegais.

Nos estabelecimentos do circuito inferior que vendem produtos in natura, a premissa trazida por Santos (2004) de que o circuito inferior estabelece relações muito fortes com o local e desprezíveis com o internacional se mostra válida. Um fenômeno crescente e que Santos não poderia ter previsto (seu texto original remonta ao ano de 1979) é a invasão de produtos chineses, tanto no circuito inferior quanto no superior. Ainda assim, é possível uma análise em separado à medida em que a diferença na tipologia dos produtos chineses aponta para a concentração de produtos de maior valor no circuito superior e os de menor valor no circuito inferior. 
A formação de dois circuitos da economia urbana por intermédio da ação do Estado: o caso de Cobija (Bolivia)

FIGURA 7 - Aspecto do circuito inferior da economia urbana de Cobija: Pequeno mercado situado na avenida 9 de fevereiro

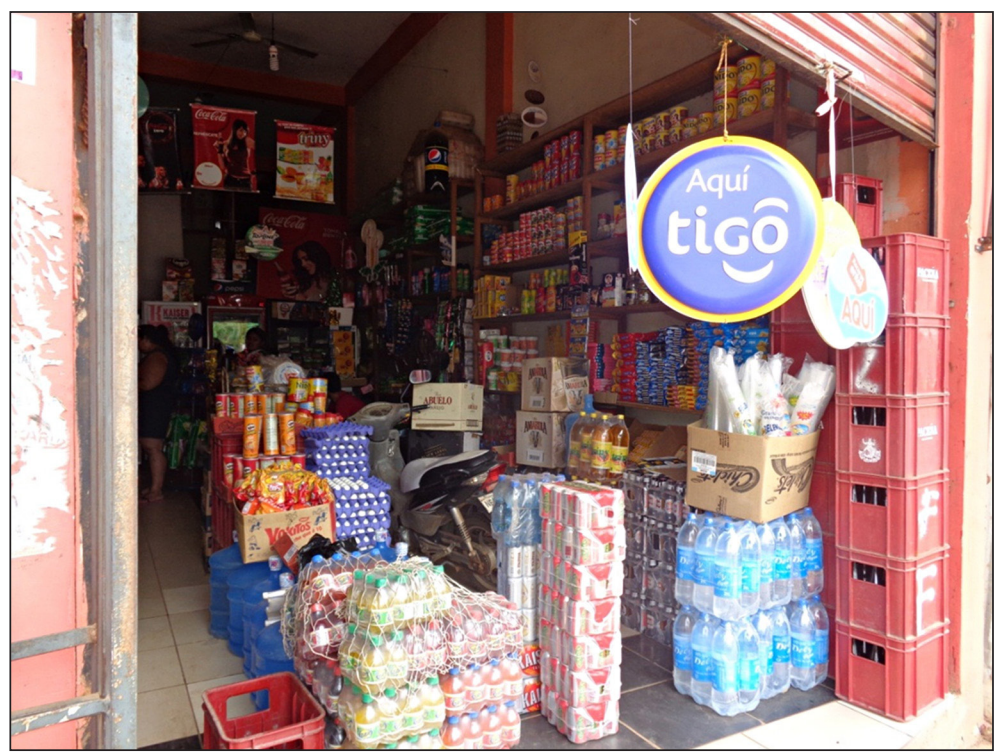

Fonte: Foto do autor

FIGURA 8 - Aspecto do circuito inferior da economia urbana de Cobija: Feira Comercial situada na avenida 9 de Fevereiro

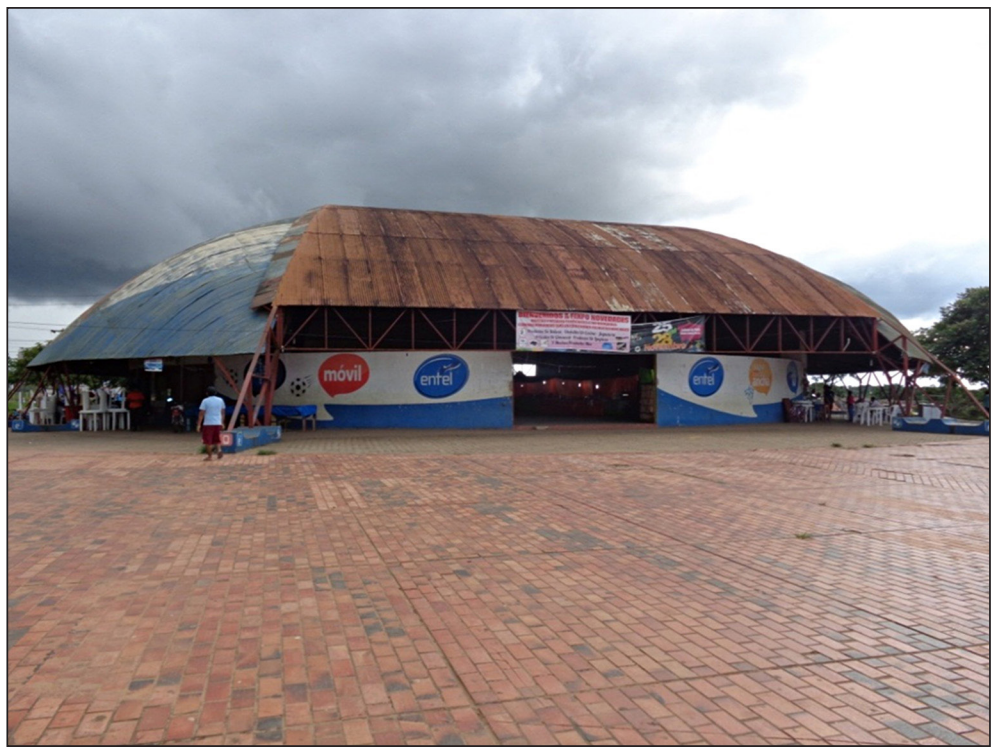

Fonte: Foto do autor 


\section{Considerações finais}

Por se posicionar em uma região estratégica e pelo fato da Bolívia ter registrado um histórico de perdas territoriais marcantes, Cobija está submetida a uma política territorial agressiva: constitui-se como uma das diversas Zonas Francas bolivianas. Tal regulamentação favorece a importação de produtos livres de certos impostos, fazendo com que o comércio ofereça produtos de alto padrão da Europa e dos Estados Unidos. Contudo, tais produtos não são acessíveis (por motivos econômicos) ao consumidor boliviano médio, fazendo com que o arranjo urbano da cidade pronuncie de forma notória os fundamentos do modelo dos dois circuitos da economia urbana de Milton Santos (2004). As desigualdades espaciais pronunciadas são passíveis de serem agrupadas naquilo que o autor chamou de circuito superior (que comercializa produtos de alto padrão e mantém relações de clientela e abastecimento com o exterior) e circuito inferior da economia urbana (centrado principalmente na alimentação e no vestuário, com clientela centrada nos habitantes da própria cidade).

As condições sui generis às quais Cobija está submetida ajudam a entender a contradição encontrada frente ao modelo de Santos (2004): o circuito inferior se abastece, pelo menos no que tange ao setor de produtos de alimentação de origem industrial, principalmente do mercado brasileiro.

O estudo de caso apresentado mostra de forma notória como o Estado pode, por intermédio de suas políticas territoriais especiais, modificar a realidade mercantil e o arranjo social de uma cidade. Mostra, assim, como a interferência do Estado na ordem mercantil atua drasticamente na ordem social.

\section{THE FORMATION OF TWO CIRCUITS OF URBAN ECONOMY THROUGH the action of the State: the case of CobiJa (Bolivia)}

ABSTRACT: Located on the Bolivian territorial periphery, the city of Cobija, capital of the Department of Pando, has a special territorial policy: the regulation of a Free Trade Zone. The state's action in regards to territorial planning highlighted the premises of Milton Santos' (2004) model of the two urban economy circuits. This paper highlights the manner in which the State can, through policies that interfere with the mercantile order, spatially segregate the urban space and promote the rearrangement of the social order.

KEYWORDS: Free Zone. State. Trade Order. Social Order. 
A formação de dois circuitos da economia urbana por intermédio da ação do Estado: o caso de Cobija (Bolivia)

\section{REFERÊNCIAS}

BOLIVIA. Embajada del Bolivia em Brasil. Directorio de zonas francas. Disponível em: http://www.embolivia.org.br/nota.php?idn=43. Acesso em: 18 jul. 2015.

CARLO, Carol. Grupos econômicos em el comercio de importaciones: Cobija, migración y zona franca. T'inkazos, La Paz, número 33, 2013, p.47-66.

COELHO, Karla Nunes de Barros. O planejamento urbano regional e a sua importância para as cidades de fronteira. In: XV ENANPUR Encontro Nacional da Associação Nacional de Pós-graduação e Pesquisa em Planejamento Urbano e Regional. 2013, Recife, Anais do XV ENANPUR Encontro Nacional da Associação Nacional de Pós-graduação e Pesquisa em Planejamento Urbano e Regional, 2013, v. XV, p.1-12.

DINIZ, Alexandre Magno Alves; CAMPOLINA, Maíra. Raízes histórico-geográficas da formação e dilapidação do território boliviano. Boletim de Geografia Teorética, Rio Claro, volume 31, número 3, set/dez, 2006, p.505-526.

INE, Instituto Nacional de Estatística. Nota de Prensa. Cobija Tiene uno de los mayores crecimientos poblacionales del siglo XXI, 2015. Disponível em: http://www.ine.gob.bo/pdf/ boletin/NP_2015_13. Acesso em: 29 nov. 2015a.

. Ficha Resumén Censo población e Vivenda 2001. Disponível em: http://www. ine.gob.bo. Acesso em: 15 nov. 2015b.

. Ficha Resumén Censo población e Vivenda 1992. Disponível em: http://www. ine.gob.bo. Acesso em: 15 nov. 2015c.

Ficha Resumén Censo población e Vivenda 2012. Disponível em: http:// censosbolivia.ine.gob.bo/censofichacomunidad/. Acesso em: 10 nov. 2015d.

KLEIN, Hebert S. A concise history of Bolivia. New York: Cambridge University Press, Second Edition, 2011, p.361.

LA ZONA FRANCA de Cobija, Pando, generó \$US 110 millones em 2012. La Razón, La Paz, 12 de Mayo de 2013, caderno Economía Bolivia. Disponível em: http://www. economiabolivia.net/2013/05/12/la-zona-franca-de-cobija-pando-genero-us-110-millonesen-2012/. Acesso em: 29 nov. 2015.

MACHADO, Lia Osório. et.al. O desenvolvimento da faixa de fronteira: uma proposta conceitual-metodológica. In: OLIVEIRA, T.C.M. de (Org.). Território sem limites: estudo sobre as fronteiras. Campo Grande: UFMS, 2005, 87-112.

MACHADO, Lia Osório; RIBEIRO, Letícia Parente; MONTEIRO, Lício Caetano do Rego. Geopolítica fragmentada: interações transfronteiriças entre o Acre (BR), o Peru e a Bolívia. 
Cuadernos de Geografía: Revista Colombiana de Geografia. Bogotá, Volume 23, Número 2, Jul/Dez de 2014, p.15-30.

MINISTÉRIO DAS RELAÇÕES EXTERIORES, República Federativa do Brasil. Intercâmbio comercial brasileiro: Países e blocos. Brasília. Disponível em: http://www. mdic.gov.br/sitio/interna/interna.php?area=5\&menu=576. Acesso em: 13 dez. 2015.

OLIVEIRA, Tito Carlos Machado e FERREIRA, Fernanda Loureiro. A fronteira BrasilBolívia na rede de distribuição de roupas de segunda mão. Salvador: Revista Geotextos, Vol 11, número 2, p.63-88, 2015.

REYES, Fernando Siliano. As perdas territoriais do Estado Boliviano. Espaço e Tempo, São Paulo, Edição especial, p.161-181, 2009.

SANTOS, Milton. O espaço dividido. São Paulo: Edusp, 2. ed., 2004, 433 p.

SANTOS, Milton. Por uma outra globalização. Rio de Janeiro: Record, 2012a, 174 p.

SANTOS, Milton. A natureza do espaço. São Paulo: Edusp, 2012b, 384 p.

SILVA, Ricardo Marques; OLIVEIRA, Tito Carlos Machado de. O mérito das cidadesgêmeas nos espaços fronteiriços. Observatório Ibero Americano Del Desarrolo Local Y La Economia Social, Málaga, Ano 1, Número 5, p.1-11, Dezembro de 2008.

TERENCIANI, Cirlani. Interculturalidade e "Cidades-Gêmeas": ¿novas configurações identitárias? En: Contribuciones a las Ciencias Sociales, Febrero 2012. Disponível em: www.eumed.net/rev/cccss/18/. Acesso em: 30 nov. 2017.

Recebido em 29/06/2017.

Aprovado em 25/11/2017. 